\title{
Models to estimate maternal effects for juvenile body weight in broiler chickens
}

\author{
ANM Koerhuis ${ }^{1 *, 2}, \mathrm{R}$ Thompson ${ }^{3 * *}$ \\ 1 Ross Breeders Ltd, Newbridge, Midlothian EH28 8SZ, UK; \\ ${ }^{2}$ Institute of Cell, Animal and Population Biology, \\ University of Edinburgh, EH9 3JT, UK; \\ ${ }^{3}$ Roslin Institute (Edinburgh), Roslin, Midlothian EH25 9PS, UK
}

(Received 21 May 1996; accepted 7 March 1997)

Summary - The estimation of genetic and environmental maternal effects by restricted maximum likelihood was considered for juvenile body weight (JBWT) data on 139534 and 174668 broiler chickens from two populations. Of the biometrical models usually assumed in the estimation of maternal effects ('reduced Willham' models), a genetic model allowing for direct and maternal genetic effects with a covariance between them and a permanent environmental maternal effect provided the best fit. The maternal heritabilities (0.04 and 0.02) were low compared to the direct heritabilities $(0.32$ and 0.27$)$, the directmaternal genetic correlations $\left(r_{\mathrm{AM}}\right)$ were negative and identical for both strains $(-0.54)$ and environmental maternal effects of full sibs (0.06 and 0.05$)$ were approximately a factor of two greater than maternal half sibs $(0.03$ and 0.02$)$. A possible environmental dam-offspring covariance was accounted for in the mixed model by (1) estimation of the covariance between the environmental maternal and the environmental residual effects $\left(c_{\mathrm{EC}}\right)$ and (2) a maternal phenotypic effect through regression on the mother's phenotype $\left(F_{\mathrm{m}}\right.$, 'Falconer' model). Whilst increasing the likelihoods considerably, these extended models resulted in somewhat more negative $r_{\mathrm{AM}}$ values owing to positive estimates of $c_{\mathrm{EC}}$ (0.04-0.08 and 0.03-0.09) and $F_{\mathrm{m}}(0.01-0.14$ and $0.01-0.11)$. A more detailed fixed effects model, accounting for environmental effects due to individual parental flocks, reduced estimates of $r_{\mathrm{AM}}(-0.18$ to -0.33$)$. Results suggested a limited importance of maternal genetic effects exerting a non-Mendelian influence on JBWT. The present integrated 'Falconer-Willham' models allowing for both maternal genetic (co)variances and maternal action through regression on the mother's phenotype in a mixed model setting might offer attractive alternatives to the commonly used 'Willham' models for mammalian species (eg, beef cattle) as was illustrated by their superior goodness-of-fit to simulated data.

broiler chickens / juvenile body weight / maternal effects / restricted maximum likelihood / animal model

* Correspondence and reprints.

** Present address: Statistics Department, IACR-Rothamsted, Harpenden, Hertfordshire AL5 2 JQ, UK. 
Résumé - Modèles d'estimation des effets maternels sur le poids corporel jeune des poulets de chair. L'estimation des effets maternels génétiques et non génétiques sur le poids jeune (JBWT) a été effectuée par maximum de vraisemblance restreinte sur 139534 et 174668 données provenant de deux populations de poulets de chair. Parmi les modèles habituellement utilisés dans l'estimation des effets maternels (modèles « réduits» de Willham), le meilleur ajustement a été obtenu avec un modèle génétique permettant des effets génétiques directs et maternels corrélés ainsi qu'un effet maternel permanent non génétique. Les héritabilités maternelles $(0,04$ et 0,02$)$ ont été faibles en comparaison des héritabilités directes (0,32 et 0,27), les corrélations génétiques entre effets directs et maternels $\left(r_{\mathrm{AM}}\right)$ ont été négatives et identiques pour les deux souches $(-0,54)$, les effets maternels non génétiques pour les pleins frères $(0,06$ et 0,05$)$ ont été environ deux fois plus grands que pour les demi-frères (0,03 et 0,02). On a tenu compte d'une covariance non génétique possible entre mère et produit dans le modèle mixte i) en estimant la covariance entre les effets maternels non génétiques et les effets résiduels non génétiques $\left(\sigma_{\mathrm{EC}}\right)$ et ii) en introduisant in effet maternel phénotypique au travers de la régression sur la phénotype de la mère ( $F_{\mathrm{m}}$ dans le modèle de Falconer). Bien qu'ils augmentent considérablement les vraisemblances, ces modèles étendus ont abouti à des valeurs encore plus négative de $r_{\mathrm{AM}}$ à cause d'estimées positives de $\sigma_{E C}(0,04$ à 0,08 et 0,03 à 0,09$)$ et $F_{\mathrm{m}}(0,01$ à 0,14 et 0,01 à 0,11$)$. Un modèle plus détaillé pour les effets fixés tenant compte des effets de milieu propres aux troupeaux parentaux a réduit les estimées de $r_{\mathrm{AM}}(-0,18$ $\grave{a}-0,33)$. Les résultats ont suggéré une importance limitée des effets maternels génétiques non mendéliens sur JBWT. Les modèles intégrés «Falconer-Willham» permettant à la fois des co(variances) maternelles génétiques et une action maternelle via le phénotype de la mère dans un modèle mixte pourraient offrir des alternatives intéressantes aux modèles de «Willham» couramment utilisés pour les mammifères (par exemple, bovins allaitants) comme il apparaît d'après leur meilleur ajustement à des données simulées.

poulet de chair / poids juvénile / effets maternels / maximum de vraisemblance restreinte / modèle animal

\section{INTRODUCTION}

At present, estimation of maternal genetic variances in animal breeding is mainly based on the biometrical model suggested by Willham (1963). This model of maternal inheritance assumes a single (unobserved) maternal trait, inherited in a purely Mendelian fashion, producing a non-Mendelian effect on a separate trait in the offspring. For instance, the dam's milk production and mothering ability might exert a combined non-Mendelian influence on early growth rate of beef cattle (Meyer, 1992a). The practical application of such models has been greatly facilitated and hence encouraged by derivative-free IAM-REML programs of Meyer (1989), in which estimation of genetic maternal effects according to Willham (1963) forms a standard feature. Meyer (1989), however, uses a 'reduced' model by assuming absence of an environmental dam-offspring covariance, which is likely to improve the precision of the often highly confounded components to be estimated but which might at the same time lead to biased estimates of the correlation between the direct and the maternal genetic effects $\left(r_{\mathrm{AM}}\right)$ in particular (Koch, 1972; Thompson, 1976; Meyer, 1992a, b). Often the types of covariances between relatives available in the data do not have sufficiently different expectations to allow all components of Willham's (1963) model to be estimated (Thompson, 1976; Meyer, 1992b). For example, for a data set (of size 8000 ) based on a genetic parameter structure typical 
of a growth trait in beef cattle, Meyer (1992b) found that the environmental damoffspring covariance should amount to at least $30 \%$ of the permanent environmental variance due to the dam before a likelihood ratio test would be expected to distinguish it from zero. Greater data sets, however, including multiple generations of observations and a variety of types of covariances between relatives might provide sufficient contrast for the higher number of components in an extended model to be estimated more precisely.

Falconer (1965) considered the case where the phenotypic value of the mother for the character in question influenced the value of the offspring for the same character, which results in an environmentally caused dam-offspring resemblance. To account for this resemblance statistically, he included a partial regression coefficient in the model, which related daughters' to mothers' phenotypic values in the absence of genetic variation among the mothers. The genetic basis of the maternal effect is ignored in such a model. Thompson (1976) investigated Falconer's (1965) approach, using maximum likelihood methods, as an alternative to Willham's (1963) model with low precision and high sampling covariances between some estimates.

Lande and Kirkpatrick (1990) showed that Willham's (1963) model fails to account for cycles of maternal effects as in Falconer's (1965) model. Robinson (1994) demonstrated by simulation that a negative dam-offspring regression, as in Falconer's model with a regression coefficient of -0.2 , was fitted by Willham's model partially as a negative $r_{\mathrm{AM}}$ and as a permanent environmental effect using Meyer's IAM-REML programs. Consequently, she argued that such negative covariance might explain the often disputed negative $r_{\mathrm{AM}}$ estimates.

Because of these mutual limitations it might be interesting to integrate Falconer's and Willham's models in a mixed model setting to enable consideration of both the genetic basis of the maternal effect and the maternal action through regression on the phenotype of the mother (corrected for BLUE solutions of fixed effects).

A great amount of work has been carried out on the estimation of maternal effects among domestic livestock, in particular for mammals (see Willham, 1980; Mohiuddin, 1993; Robinson, 1996). In poultry, however, where maternal (egg) effects on juvenile broiler body weight (JBWT) are apparent (Chambers, 1990), no major attempts have been made to partition this maternal variance into genetic and environmental components. Also the sign and magnitude of $r_{\mathrm{AM}}$ has not been estimated according to Willham's (1963) model. Although many studies have shown a positive (phenotypic) effect of egg weight on JBWT (Chambers, 1990). Such poultry data may be suitable for the estimation of maternal genetic variances owing to their size and structure with many offspring per dam and often many recorded generations available.

The objectives of the present study were to investigate (1) the effect of estimation of the environmental dam-offspring covariance on the other (co)variance components and resulting parameters (particularly $r_{\mathrm{AM}}$ ) and on the likelihood of the sizeable data sets for JBWT in two meat-type chicken populations by IAM-REML methods and (2) the goodness-of-fit of Falconer-type and integrated FalconerWillham models to simulated data and these JBWT data and the resulting estimated components and parameters. 


\section{MATERIAL AND METHODS}

\section{Data}

\section{Field data}

The data on JBWT originated from two commercial broiler populations. Summary statistics are illustrated in table I. The data on strains A and B represented approximately six and three overlapping generations, respectively. Male and female JBWT SDs were somewhat heterogeneous, presumably, because of a scale effect. Some heterogeneity of raw CVs was apparent, but disappeared after precorrection for effects of hatch week and age of the dam. Some data structure aspects are shown in table II.

Table I. Summary statistics for juvenile body weight $(\mathrm{kg} / 100)$ in two broiler populations with raw and corrected SDs and CVs.

\begin{tabular}{lcrccccc}
\hline \multirow{2}{*}{ Strain } & Sex & Records & Mean & $S D_{\text {raw }}{ }^{a}$ & $C V_{\text {raw }}(\%)$ & $S D_{\text {cor }}{ }^{b}$ & $C V_{\text {cor }}(\%)$ \\
\hline A & combined & 139534 & 224.9 & 29.9 & 13.3 & 19.6 & 8.7 \\
& male & 68334 & 241.7 & 27.3 & 11.3 & 21.1 & 8.7 \\
& female & 71200 & 208.8 & 22.6 & 10.8 & 17.9 & 8.6 \\
B & combined & 174668 & 195.3 & 25.4 & 13.0 & 15.6 & 8.0 \\
& male & 85325 & 211.4 & 21.8 & 10.3 & 16.9 & 8.0 \\
& female & 89343 & 179.9 & 18.0 & 10.0 & 14.2 & 7.9 \\
\hline
\end{tabular}

${ }^{a}$ Raw data; ${ }^{b}$ data corrected for hatch and age of dam effects; combined data also corrected for sex effect.

Table II. Some structural aspects of the data for juvenile body weight in the two broiler populations.

\begin{tabular}{lccccc}
\hline Strain & Records & Animals & Sires & Dams & $\begin{array}{c}\text { Sire-dam } \\
\text { combinations }\end{array}$ \\
\hline A & 139534 & 140983 & 856 & 5879 & 8337 \\
B & 174668 & 177294 & 698 & 5318 & 6819 \\
\hline
\end{tabular}

\section{Simulated data}

Data were simulated to study the goodness-of-fit of the various models to estimate maternal effects (see the following) and the differences between simulated and estimated (co)variance components. The genetic model was similar to the one assumed by Robinson (1994), with a direct genetic effect, a maternal genetic effect 
and a residual effect, sampled from $\mathrm{N}(0,100), \mathrm{N}(0,20)$ and $\mathrm{N}(0,280)$, respectively. Furthermore, a regression of -0.1 on the phenotype of the dam was assumed. The base population consisted of 110 animals. Ten sires were mated to 100 dams in a nested design with ten full sib offspring produced by each sire-dam combination. Parental candidates were randomly assigned from these thousand offspring to generate the next generation. This hierarchical mating scheme was repeated for eight generations.

\section{Models of analyses}

\section{Effects of location}

Fixed effects fitted were hatch week (198 and 90 levels for strains A and B, respectively), sex (two levels) and age of the dam when the egg was laid in 3-week intervals (seven levels) representing effects on eggs (eg, size).

\section{Considering male and female JBWT as separate traits}

Table I gave some evidence that the differential SDs of both sexes are due to the dependence of variance and mean, since adjusted CVs were homogeneous. To fully justify evaluation of male and female JBWT as one trait in the analysis of maternal effects, however, the two sexes were considered as separate traits in a bivariate analysis in order to investigate the genetic relationship between these traits and hence the importance of segregation of sex-linked genes affecting JBWT in the present broiler populations. In matrix notation the bivariate model can be presented as:

$$
\left[\begin{array}{l}
\mathbf{y}_{1} \\
\mathbf{y}_{2}
\end{array}\right]=\left[\begin{array}{cc}
\mathbf{X}_{1} & 0 \\
0 & \mathbf{X}_{2}
\end{array}\right]\left[\begin{array}{l}
\mathbf{b}_{1} \\
\mathbf{b}_{2}
\end{array}\right]+\left[\begin{array}{cccc}
\mathbf{Z}_{\mathrm{a} 1} & 0 & \mathbf{Z}_{\mathrm{c} 1} & 0 \\
0 & \mathbf{Z}_{\mathrm{a} 2} & 0 & \mathbf{Z}_{\mathrm{c} 2}
\end{array}\right]\left[\begin{array}{l}
\mathbf{a}_{1} \\
\mathbf{a}_{2} \\
\mathbf{c}_{1} \\
\mathbf{c}_{2}
\end{array}\right]+\left[\begin{array}{l}
\mathbf{e}_{1} \\
\mathbf{e}_{2}
\end{array}\right]
$$

where, for trait $i$ ( $i=1,2$; representing JBWT on males and females), $\mathbf{y}_{i}$ is a vector of observations; $\mathbf{b}_{i}$ is a vector of fixed effects; $\mathbf{a}_{i}$ is a vector with random additive genetic animal effects; $\mathbf{c}_{i}$ is a vector with random maternal permanent environmental effects; $\mathbf{e}_{i}$ is a vector with random residual effects; and $\mathbf{X}_{i}, \mathbf{Z}_{a i}$ and $\mathbf{Z}_{c i}$ are incidence matrices relating the observations to the respective fixed and random effects. The assumed variance--covariance structure is:

$$
\mathbf{V}\left[\begin{array}{l}
\mathbf{u} \\
\mathbf{e}
\end{array}\right] \equiv \mathbf{V}\left[\begin{array}{l}
\mathbf{a}_{1} \\
\mathbf{a}_{2} \\
\mathbf{c}_{1} \\
\mathbf{c}_{2} \\
- \\
\mathbf{e}_{1} \\
\mathbf{e}_{2}
\end{array}\right]=\left[\begin{array}{cccc|cc}
\mathbf{A} \sigma_{\mathrm{a} 1}^{2} & \mathbf{A} \sigma_{\mathrm{a} 12} & 0 & 0 & 0 & 0 \\
\mathbf{A} \sigma_{\mathrm{a} 12} & \mathbf{A} \sigma_{\mathrm{a} 1}^{2} & 0 & 0 & 0 & 0 \\
0 & 0 & \mathbf{I}_{1} \sigma_{\mathrm{c} 1}^{2} & \mathbf{B} \sigma_{\mathrm{c} 12} & 0 & 0 \\
0 & 0 & \mathbf{B} \sigma_{\mathrm{c} 12} & \mathbf{I}_{2} \sigma_{\mathrm{c} 2}^{2} & 0 & 0 \\
\hline 0 & 0 & 0 & 0 & \mathbf{I}_{1} \sigma_{\mathrm{e} 1}^{2} & 0 \\
0 & 0 & 0 & 0 & 0 & \mathbf{I}_{2} \sigma_{\mathrm{e} 2}^{2}
\end{array}\right]
$$

where $\sigma_{\mathrm{a} i}^{2}, \sigma_{\mathrm{c} i}^{2}$ and $\sigma_{\mathrm{e} i}^{2}$ are the additive genetic, the maternal permanent environmental and the residual environmental variances for trait $i ; \sigma_{\mathrm{a} 12}$ and $\sigma_{\mathrm{c} 12}$ are the 
corresponding covariances between the male and female JBWT; $\mathbf{A}$ is the relationship matrix; $\mathbf{I}_{i}$ is an identity matrix; and $\mathbf{B}$ is a rectangular matrix linking male and female progeny records to the dam. The algorithm of Thompson et al (1995) was used. Their method reduces the model to univariate forms by scaling and transformation, which diminishes dimensionality and speeds up convergence.

Table III. Fitted random effects and estimated (co)variance components in the six initial models of analysis ${ }^{\mathrm{a}}$.

\begin{tabular}{|c|c|c|c|c|c|c|c|c|c|c|}
\hline \multirow{2}{*}{$\begin{array}{l}\text { Model } \\
\text { No }\end{array}$} & \multicolumn{4}{|c|}{ Fitted $^{\mathrm{b}}$} & \multicolumn{6}{|c|}{ Estimated $^{\mathfrak{c}}$} \\
\hline & $\mathrm{a}$ & $\mathrm{m}$ & $\mathrm{c}_{H S}$ & $\mathrm{c}_{\mathrm{FS}}$ & $\sigma_{A}^{2}$ & $\sigma_{M}^{2}$ & $\sigma_{A M}$ & $\sigma_{C_{H S}}^{2}$ & $\sigma_{C_{F S}}^{2}$ & $\sigma_{E}^{2}$ \\
\hline 1 & - & & & & - & & & & & - \\
\hline $2 a$ & - & & - & & - & & & - & - & - \\
\hline $2 \mathrm{~b}$ & - & & & - & - & & & & - & - \\
\hline $2 c$ & - & & - & - & - & & & - & - & - \\
\hline 3 & - & - & & & - & - & & & & - \\
\hline 4 & - & - & & & - & - & - & & & - \\
\hline $5 \mathbf{a}$ & - & - & - & & - & - & & - & - & - \\
\hline $5 b$ & - & - & & - & - & - & & & - & - \\
\hline $5 c$ & - & - & - & - & - & - & & - & - & - \\
\hline $6 a$ & - & - & - & & - & - & - & - & - & - \\
\hline $6 \mathrm{~b}$ & - & - & & - & - & - & - & & - & - \\
\hline $6 c$ & - & - & - & - & - & - & - & - & - & - \\
\hline
\end{tabular}

${ }^{\mathrm{a}}$ Revised after Meyer (1989); ${ }^{\mathrm{b}}$ direct additive genetic effect; $m$ : maternal genetic effect; $c$ : maternal environmental effect on maternal half sibs (HS) and full sibs (FS); ${ }^{c} \sigma_{\mathrm{A}}^{2}$ : direct additive genetic variance; $\sigma_{\mathrm{M}}^{2}$ : maternal additive genetic variance; $\sigma_{\mathrm{AM}}$ : direct-maternal genetic covariance; $\sigma_{\mathrm{C}}^{2}$ : common maternal permanent environmental variance on maternal HSs and FSs; and $\sigma_{\mathrm{E}}^{2}$ : error variance.

\section{A 'reduced' Willham model}

Initially six different genetic models, applied by Meyer (1989), were considered for both strains.

Table III exhibits the random effects fitted and the (co)variance components estimated in each model. Model 1 was a purely direct additive model, while model 2 (with sub-models a,b and c) allowed for dams' permanent environmental effects in addition. This environmental maternal component was slightly expanded by distinguishing between a covariance of maternal half sibs $\left(c_{\mathrm{HS}}^{2}\right.$, model 2a) and full sibs $\left(c_{\mathrm{FS}}^{2}\right.$, model $2 \mathrm{~b}$ ). Fitting both simultaneously was considered also (model $2 \mathrm{c}$ ). When only fitting $c_{\mathrm{HS}}^{2}$ then $c_{\mathrm{FS}}^{2}=c_{\mathrm{HS}}^{2}$ (see table III), since covariance amongst maternal HSs also applies to FSs. Model 3 included a maternal genetic effect in addition to the animals' direct genetic effects, assuming zero direct-maternal covariance $\left(\sigma_{\mathrm{AM}}\right)$. Model 4 was as model 3 but allowed for a non-zero $\sigma_{\mathrm{AM}}$. Models 5 and 6 ( $\mathrm{a}, \mathrm{b}$ and $\mathrm{c}$ ) corresponded to models 3 and 4 , respectively, but included 
maternal permanent environmental effects in addition (on maternal HSs and/or FSs). The sub-models (1-5) follow from the full mixed linear model (model 6), which in matrix notation is:

$$
\mathbf{y}=\mathbf{X b}+\mathbf{Z}_{\mathrm{A}} \mathbf{u}_{\mathrm{A}}+\mathbf{Z}_{\mathrm{M}} \mathbf{u}_{\mathrm{M}}+\mathbf{Z}_{\mathrm{C}} \mathbf{c}+\mathbf{e}
$$

where $\mathbf{y}, \mathbf{b}, \mathbf{u}_{\mathrm{A}}, \mathbf{u}_{\mathrm{M}}, \mathbf{c}$ and $\mathbf{e}$ are vectors of observations, fixed effects, direct breeding values, maternal breeding values, random common maternal permanent environmental effects, and random environmental residual effects, respectively; and $\mathbf{X}, \mathbf{Z}_{\mathrm{A}}, \mathbf{Z}_{\mathrm{M}}$ and $\mathbf{Z}_{\mathrm{C}}$ are incidence matrices relating the observations to the respective fixed and random effects. The variance-covariance structure is

$$
\operatorname{var}\left[\begin{array}{c}
u_{\mathrm{a}} \\
u_{\mathrm{m}} \\
c \\
e
\end{array}\right]=\left[\begin{array}{cccc}
\mathbf{A} \sigma_{\mathrm{A}}^{2} & \mathbf{A} \sigma_{\mathrm{AM}} & 0 & 0 \\
\mathbf{A} \sigma_{\mathrm{AM}} & \mathbf{A} \sigma_{\mathrm{M}}^{2} & 0 & 0 \\
0 & 0 & \mathbf{I} \sigma_{\mathrm{C}}^{2} & 0 \\
0 & 0 & 0 & \mathbf{I} \sigma_{\mathrm{E}}^{2}
\end{array}\right]
$$

where $\sigma_{\mathrm{C}}^{2}$ represents either the covariance between FSs or maternal HSs.

\section{An 'extended' Willham model}

Throughout the previous models a zero direct-maternal environmental covariance $\left(\sigma_{\mathrm{EC}}\right)$ was assumed, which is commonly practiced. However, the possibility of a nonzero $\sigma_{\mathrm{EC}}$ is real. The existence of a negative $\sigma_{\mathrm{EC}}$, for example, has been suggested (eg, Koch, 1972). Ignoring a (non-zero) $\sigma_{\mathrm{EC}}$ is likely to bias the parameters involved in the estimation of maternal effects. In particular $\sigma_{\mathrm{AM}}$ might be biased in a downward direction when ignoring a $\sigma_{\mathrm{EC}}$ that is negative. Therefore, $\sigma_{\mathrm{EC}}$ was included in all models in a second series of runs (models 7-12) to study changes in estimated components and parameters and goodness-of-fit. The (co)variance structure now is

$$
\operatorname{var}\left[\begin{array}{c}
u_{\mathrm{a}} \\
u_{\mathrm{m}} \\
c \\
e
\end{array}\right]=\left[\begin{array}{cccc}
\mathbf{A} \sigma_{\mathrm{A}}^{2} & \mathbf{A} \sigma_{\mathrm{AM}} & 0 & 0 \\
\mathbf{A} \sigma_{\mathrm{AM}} & \mathbf{A} \sigma_{\mathrm{M}}^{2} & 0 & 0 \\
0 & 0 & \mathbf{I} \sigma_{\mathrm{C}}^{2} & \mathbf{B} \sigma_{\mathrm{EC}} \\
0 & 0 & \mathbf{B} \sigma_{\mathrm{EC}} & \mathbf{I} \sigma_{\mathrm{E}}^{2}
\end{array}\right]
$$

Consequently, three maternal environmental covariances were conceivable, a covariance amongst maternal half sibs, a covariance amongst full sibs and a covariance between dam and offspring. When only fitting $c_{\mathrm{EC}}$ then $c_{\mathrm{FS}}^{2}=c_{\mathrm{HS}}^{2}=c_{\mathrm{EC}}$, since $c_{\mathrm{EC}}$ also applies to the covariance amongst maternal HSs and FSs.

\section{The (direct) Falconer model}

Falconer (1965) suggested a model including a maternal effect $\left(F_{\mathrm{m}}\right)$ as linear function of the mother's phenotype (see outline in Appendix). Thompson (1976) derived the expectations for $\sigma_{\mathrm{P}}^{2}$ and $\sigma_{\mathrm{A}}^{2}$ in terms of $F_{\mathrm{m}}$ for the sources of (co)variation frequently used for animal breeding data, making inferences about $\mathbf{y}$ rather than 
$\left(\mathbf{y}-F_{\mathrm{m}} y^{\prime}\right)$. In a mixed model setting this model (ignoring the dominance component) can be formulated in matrix notation as

$$
\mathbf{y}=\mathbf{X b}+F_{\mathrm{m}}\left(\mathbf{y}_{\mathrm{P}}-\mathbf{X}_{\mathrm{P}} \mathbf{b}\right)+\mathbf{Z}_{\mathrm{A}} \mathbf{u}_{\mathrm{A}}+\mathbf{Z}_{\mathrm{C}} \mathbf{c}+\mathbf{e}
$$

where $\mathbf{y}_{\mathrm{P}}$ is a vector with the dams' observations and $\mathbf{X}_{\mathrm{P}}$ is the incidence matrix relating these observations to the respective fixed effects.

\section{An integrated Falconer-Willham model}

To account for possible maternal pathways through the dam's phenotype as well as the genetic origin of maternal effects an integrated approach was investigated in a third series of runs (models 13-18). The matrix representation of the full linear integrated Falconer-Willham model that was considered is

$$
\mathbf{y}=\mathbf{X} \mathbf{b}+F_{\mathrm{m}}\left(\mathbf{y}_{\mathrm{P}}-\mathbf{X}_{\mathrm{P}} \mathbf{b}\right)+\mathbf{Z}_{\mathrm{A}} \mathbf{u}_{\mathrm{A}}+\mathbf{Z}_{\mathrm{M}} \mathbf{u}_{\mathrm{M}}+\mathbf{Z}_{\mathrm{C}} \mathbf{c}+\mathbf{e}
$$

which is Willham model (2) and Falconer model (3) amalgamated. The Appendix provides a derivation of the variance of $\mathbf{y}$.

For models with a maternal effect the fraction of the selection differential that would be realised if selection were on phenotypic values $\left(h_{\mathrm{A}+\mathrm{M}}^{2}\right)$, ie, the regression of the sum of direct and maternal genotypes on the phenotype was calculated as (Willham, 1963):

$$
h_{\mathrm{A}+\mathrm{M}}^{2}=\left(\sigma_{\mathrm{A}}^{2}+1.5 \sigma_{\mathrm{AM}}+0.5 \sigma_{\mathrm{M}}^{2}\right) / \sigma_{\mathrm{P}}^{2}
$$

where $\sigma_{\mathrm{A}}^{2}$ is the direct additive genetic variance, $\sigma_{\mathrm{M}}^{2}$ is the maternal additive genetic variance and $\sigma_{\mathrm{P}}^{2}$ is the phenotypic variance.

\section{Methods of analyses}

\section{Henderson-III and offspring-parent regression}

Henderson's method III was applied to the data to produce estimates of variance due to sires (patHS) and sire-dam combinations (FS). A weighted average of the individual generation estimates was obtained by weighing them inversely proportional to their sampling variances. Covariances between offspring and sire and dam, respectively, were obtained by weighted regression analyses (with the degrees of freedom as weights) of average offspring on parental performances, which were both deviated from OLS expectations based on the effects of location. The sources of (co)variation were equated to their expectations and the resulting system of linear equations was solved by multiple regression for a series of values for $F_{\mathrm{m}}$, thereby locating the $F_{\mathrm{m}}$ that resulted in minimisation of the mean square error or rather maximisation of the likelihood and the 'best' estimates for $\sigma_{\mathrm{P}}^{2}$ and $\sigma_{\mathrm{A}}^{2}$ (Thompson, 1976). 


\section{IAM-REML}

IAM estimates of the (co)variance components for both data sets were obtained by a derivative-free REML algorithm based on programs written by Meyer (1989). The programs were adapted to include an environmental dam-offspring covariance component and to enable the estimation of Falconer's maternal phenotypic regression, either on its own or integrated in Willham's model. Equations in the mixed model matrix (MMM), the coefficient matrix and the RHS's augmented, were reordered using a multiple minimum degree reordering (George and Liu, 1980) to minimise fill-in, before Gaussian elimination was performed on MMM. The Downhill Simplex method (Nelder and Mead, 1965) was used to locate the maximum log likelihood $(\log L)$. Convergence was assumed when the variance of the function values $(-2 \log$ $L$ ) in the Simplex was less than $10^{-8}$. For a series of values for $F_{\mathrm{m}}$, the likelihood of the remaining parameters in the Willham model was maximised given these values of $F_{\mathrm{m}}$. For the first $F_{\mathrm{m}}$ maximisation run the scaling factor for the residual variances of animals with missing maternal observations $\left(s_{\mathrm{F}}\right.$, see Appendix) was set to unity since $s_{\mathrm{F}}$ is a function of $F_{\mathrm{m}}$ and the (co)variances to be estimated. A second run was performed, for every value of $F_{\mathrm{m}}$, incorporating a scaling factor as deduced from the estimated (co)variance components and $F_{\mathrm{m}}$ (see equations A2 and A3 in Appendix). In this second run the likelihood was remaximised and adjusted for the changes in the projected data and the variance component estimates. A second update of $s_{\mathrm{F}}$ and subsequent maximisation run led to only negligible changes in likelihood and was, hence, not performed for these analyses. For every other $F_{\mathrm{m}}$ maximisation run the initial $s_{\mathrm{F}}$ value was chosen as a proportion of the previous maximised $s_{\mathrm{F}}$ value. The Falconer parameter $F_{\mathrm{m}}$ maximising the likelihood was estimated by quadratic approximation of the profile likelihood surface of $F_{\mathrm{m}}$. The accompanying parameters in the Willham model had maximum likelihood conditional to this value of $F_{\mathrm{m}}$.

Likelihood ratio tests, with error probability of $5 \%$, were carried out to determine whether maternal genetic or permanent environmental effects contributed significantly to the phenotypic variance in JBWT for both strains.

Furthermore, the asymptotic sampling variances of $\sigma_{\mathrm{AM}}$ (models $6 \mathrm{c}$ and 12c) and $\sigma_{\mathrm{EC}}$ (model 12c) were obtained by fitting quadratic Taylor polynomials to their profile log-likelihood curvatures (Smith and Graser, 1986). The profile likelihoods were $L_{\eta}\left(\sigma_{\mathrm{A} \eta}^{2}, \sigma_{\mathrm{M} \eta}^{2}, \sigma_{\mathrm{C} \eta}^{2}, \sigma_{\mathrm{E}}^{2} \mid \sigma_{\mathrm{AM} \eta}, \mathbf{y}\right), \quad L_{\eta}\left(\sigma_{\mathrm{A} \eta}^{2}, \sigma_{\mathrm{M} \eta}^{2}, \sigma_{\mathrm{C} \eta}^{2}, \sigma_{\mathrm{EC} \eta}, \sigma_{\mathrm{E}}^{2} \mid \sigma_{\mathrm{AM} \eta}, \mathbf{y}\right)$ and $L_{\eta}\left(\sigma_{\mathrm{A} \eta}^{2}, \sigma_{\mathrm{M} \eta}^{2}, \sigma_{\mathrm{C} \eta}^{2}, \sigma_{\mathrm{E}}^{2} \mid \sigma_{\mathrm{EC} \eta}, \mathbf{y}\right)$ for $\sigma_{\mathrm{AM}}$ in models 6 and 12 and for $\sigma_{\mathrm{EC}}$ in model 12 , respectively, where $\hbar$ represents the fixed point for which the log-likelihood was maximised.

\section{RESULTS}

\section{Sex-linked variation in JBWT}

Results of the bivariate analyses considering male and female JBWT as different traits are shown in table IV. Differences in male and female phenotypic variances were substantial as might be expected because of the large differences in mean performances of both sexes (table I). Although not significant, the female heritabilities 
were somewhat greater than the male heritabilities. In birds the females are the heterogametic sex. Female offspring get their sex-linked genes only from their fathers. Therefore, if significant sex-linkage is present, higher male heritabilities might be anticipated, which was not the case. Also, genetic relationships might be expected to deviate markedly from unity. However, the correlations were very high, although statistically just different from unity. We can now with more confidence say that sex-linked genes did not notably contribute to the differential variation of male and female JBWT in the present populations. Logarithmic transformation was applied to alleviate the variance-mean dependency. The comparison of genetic parameters of several models involving maternal effects did not reveal any important discrepancies between the data on the arithmetic and the geometric scales. Hence, analyses of the data on the arithmetic scale will be presented.

Table IV. Bivariate IAM-REML phenotypic variance (in $\mathrm{kg}^{2} \times 10^{-4}$ ) and dispersion parameter estimates for male and female juvenile body weight considered as separate traits.

\begin{tabular}{|c|c|c|c|c|}
\hline \multirow[b]{2}{*}{ Variance } & \multicolumn{2}{|c|}{ Strain $A$} & \multicolumn{2}{|c|}{ Strain B } \\
\hline & Male & Female & Male & Female \\
\hline $\begin{array}{l}\text { Phenotypic } \\
\text { Sex }\end{array}$ & 475 & 342 & 296 & 204 \\
\hline $\begin{array}{l}\text { Male }^{\mathrm{a}} \\
\text { Female }\end{array}$ & $\begin{array}{l}0.33 \pm 0.02 \\
0.95 \pm 0.01\end{array}$ & $0.36 \pm 0.02$ & $\begin{array}{l}0.26 \pm 0.02 \\
0.92 \pm 0.03\end{array}$ & $0.30 \pm 0.02$ \\
\hline $\begin{array}{l}\text { Male } \\
\text { Female }\end{array}$ & $\begin{array}{l}0.03 \pm 0.01 \\
0.95 \pm 0.02\end{array}$ & $0.03 \pm 0.01$ & $\begin{array}{l}0.03 \pm 0.01 \\
0.91 \pm 0.04\end{array}$ & $0.03 \pm 0.01$ \\
\hline
\end{tabular}

${ }^{\text {a }}$ Heritabilities with $\mathrm{SE}$ (based on quadratic approximation of the profile likelihood) on the diagonal and genetic correlations with SE below the diagonal; ${ }^{\mathrm{b}}$ maternal permanent environmental variances proportional to the phenotypic variances with $\mathrm{SE}$ on the diagonal and maternal permanent environmental correlations with SE below the diagonal.

\section{Conventional estimation of (co)variances, heritabilities and the Falconer parameter}

Heritability estimates based on between sire variances (paternal HS) were equal for both populations (0.21) and very similar to the offspring-sire regression estimates (0.20 and 0.19 for populations A and B, respectively) (see table V).

The heritability estimates based on FSs and offspring-dam regression were considerably higher. For population A the FS estimate was somewhat higher than the offspring-dam estimate, whereas population B showed the reverse. The components were equated to their expectations for several $F_{\mathrm{m}}$ values (table VI). The 'optimum' $F_{\mathrm{m}}$ estimates were positive with 0.03 and 0.07 for populations $\mathrm{A}$ and B, respectively. The derived heritability estimates were 0.21 and 0.19 for populations $\mathrm{A}$ and $\mathrm{B}$, respectively. 
Table V. Covariance component (in $\mathrm{kg}^{2} \times 10^{-4}$ ) and heritability estimates based on Henderson-III and offspring-parental regressions for both populations.

\begin{tabular}{lccccc}
\hline \multirow{2}{*}{\begin{tabular}{l} 
Source of \\
\cline { 5 - 6 } (co)variation
\end{tabular}} & (co) Variance & Heritability & & \multicolumn{2}{c}{ Strain 2 } \\
\cline { 2 - 3 } \cline { 5 - 6 } Paternal HS & 20.13 & 0.21 & & 13.19 & 0.21 \\
FS & 57.30 & 0.30 & & 34.37 & 0.28 \\
Within FS & 334.70 & & & \\
Offspring-dam & 53.86 & 0.27 & & 41.16 & 0.32 \\
Offspring-sire & 41.12 & 0.20 & & 24.22 & 0.19 \\
\hline
\end{tabular}

Table VI. Estimated variance components (in $\mathrm{kg}^{2} \times 10^{-4}$ ) and resulting heritabilities for a series of values for the Falconer parameter $\left(F_{\mathrm{m}}\right)$ and their respective mean square errors (MSE) with the 'optimum' results printed in bold-face for both populations.

\begin{tabular}{|c|c|c|c|c|c|c|c|c|}
\hline \multirow[t]{2}{*}{$F_{\mathrm{m}}$} & \multicolumn{4}{|c|}{ Strain 1} & \multicolumn{4}{|c|}{ Strain 2} \\
\hline & $\sigma_{P}^{2}$ & $\sigma_{A}^{2}$ & $h^{2}$ & $M S E$ & $\sigma_{P}^{2}$ & $\sigma_{A}^{2}$ & $\mathrm{~h}^{2}$ & $M S E$ \\
\hline-0.20 & 372 & 172 & 0.46 & 2302.0 & 231 & 114 & 0.49 & 1181.0 \\
\hline-0.10 & 386 & 133 & 0.34 & 766.0 & 241 & 89 & 0.37 & 472.2 \\
\hline 0.00 & 392 & 93 & 0.24 & 46.4 & 245 & 64 & 0.26 & 76.2 \\
\hline 0.03 & 392 & 82 & 0.21 & 0.3 & 246 & 57 & 0.23 & 23.5 \\
\hline 0.05 & 392 & 74 & 0.19 & 13.1 & 246 & 52 & 0.21 & 5.5 \\
\hline 0.07 & 391 & 67 & 0.17 & 60.3 & 245 & 47 & 0.19 & 1.1 \\
\hline 0.08 & 390 & 63 & 0.16 & 96.6 & 245 & 45 & 0.18 & 4.0 \\
\hline 0.10 & 389 & 56 & 0.14 & 194.2 & 244 & 40 & 0.16 & 19.7 \\
\hline 0.20 & 378 & 23 & 0.06 & 1150.0 & 238 & 19 & 0.08 & 286.5 \\
\hline
\end{tabular}

\section{IAM-REML estimation of maternal genetic parameters}

\section{Simulated data}

The goodness-of-fit of Willham, Falconer and integrated models were tested to simulated data based on an integrated Falconer-Willham model, with a direct and maternal genetic effect with zero covariance and a maternal phenotypic effect, assumed before by Robinson (1994). The results are shown in table VII. The likelihoods were deviated from model 1, which represented the appropriate genetic model. The estimated components were close to simulated components for model 1 . Model 2, representing a Willham model with direct and maternal genetic effect with non-zero covariance and a maternal environmental component, estimated a $c^{2}$-effect of 0.03 and a significantly negative estimate for $\sigma_{\mathrm{AM}}$ resulting in a negative $r_{\mathrm{AM}}$ of -0.56 , which was observed also by Robinson (1994). The likelihood ratio test adjudged the fit to be significantly worse than model 1 at a confidence level of $99 \%$. The likelihood of the Falconer model, ignoring the genetic basis of the maternal 
effect, was greater than model 2 but significantly less than model 1 with $P<0.05$. The 'full' Falconer-Willham model (model 4), assuming a non-zero $\sigma_{\mathrm{AM}}$, appeared to fit better than the true model, although the difference was not significant at $P=$ 0.05. The 'extended' Willham model (model 5) 'picked up' most of the negative environmental covariance between dam and offspring as such. However, the effect was partially fitted as a negative $\sigma_{\mathrm{AM}}$ leading to an $r_{\mathrm{AM}}$ value of -0.22 . The goodness-of-fit of model 5 was similar to the true model.

Table VII. Estimates ${ }^{a}$ of dispersion components and natural log-likelihoods and their significance $(P)$ relative to model 1 for Falconer, Willham and integrated FalconerWillham models fitted to data simulated according to model 1 assuming a direct and maternal genetic effect with zero covariance and a regression on the dam's phenotype ${ }^{\mathrm{b}}$ $\left(F_{\mathrm{m}}=-0.1\right)$.

\begin{tabular}{lrrrrrrrrrr}
\hline Model $^{\mathrm{c}}$ & $F_{m}$ & $\sigma_{A}^{2}$ & $\sigma_{M}^{2}$ & $\sigma_{A M}$ & $\sigma_{C}^{2}$ & $\sigma_{E C}$ & $\sigma_{E}^{2}$ & $\sigma_{P}^{2}$ & $\log \mathrm{L}$ & $\mathrm{P}$ \\
\hline 1 integr F-W & -0.11 & 100 & 16 & & & & 290 & 406 & 0.00 & \\
2 Willham & & 98 & 35 & -33 & 11 & & 295 & 406 & -7.91 & $<0.01$ \\
3 Falconer & -0.12 & 106 & & & 8 & & 291 & 405 & -2.91 & $<0.05$ \\
4 integr F-W & -0.11 & 109 & 15 & -11 & 4 & & 290 & 407 & 1.68 & $>0.05$ \\
5 extend W & & 109 & 15 & -9 & 6 & -32 & 322 & 411 & 0.87 & $>0.05$ \\
Input values & -0.10 & 100 & 20 & 0 & 0 & 0 & 280 & 400 & & \\
\hline
\end{tabular}

${ }^{\mathrm{a}}$ Results represent averages of 20 replications; ${ }^{\mathrm{b}}$ similar to the model assumed by Robinson (1994); ${ }^{\mathrm{c}}$ models are (1) integrated Falconer-Willham model with $\sigma_{\mathrm{AM}}=0,(2)$ Willham model, (3) Falconer model, (4) integrated Falconer-Willham model with $\sigma_{\mathrm{AM}} \neq 0$, and (5) extended Willham model with $\sigma_{\text {EC }} \neq 0$.

\section{Field data}

Estimated phenotypic variances and genetic parameters for JBWT of both strains under a series of different genetic models together with their likelihoods are summarised in tables VIII and IX. Clearly, very significant increases in log-likelihood (over model 1) demonstrate that both environmental and genetic maternal effects exist for both strains. Generally, genetic parameters were quite similar over strains, despite distinct differences in selection history.

Fitting a maternal permanent environmental effect (with the pertaining variance component as proportion of $\sigma_{\mathrm{P}}^{2}$ being referred to as $c_{\mathrm{HS}}^{2}$ for maternal half sibs (HSs) and $c_{\mathrm{FS}}^{2}$ for full sibs (FSs)) in model 2 resulted in highly significant increases in the likelihood for both strains. Estimating a $c^{2}$ for HSs and FSs simultaneously resulted in a significantly better fit with the effect of FSs being about a factor of two greater. The presence of a maternal heritability $\left(\mathrm{m}^{2}\right)$ in addition to $h^{2}$ (model 3) was much more likely than model 1 , but did not fit the data as well as model 2. Allowing for a non-zero direct-maternal genetic covariance (presented as a proportion of $\sigma_{\mathrm{P}}^{2}$ : $c_{\mathrm{AM}}$ ) in model 4 just increased the likelihood significantly (over model 3 ) for strain A. The likelihood of model 4 for strain B was, however, not significantly different from model 3 based on a likelihood ratio test $(P>0.05)$. Compared to model 3 , 
Table VIII. Estimates of phenotypic variances, genetic parameters and the relative (natural) $\log$-likelihoods ${ }^{\mathrm{a}}$ under models $1-18$ for juvenile body weight on population $\mathrm{A}$.

\begin{tabular}{|c|c|c|c|c|c|c|c|c|c|c|c|}
\hline Model & $\sigma_{P}^{2}$ & $\mathrm{~h}^{2}$ & $\mathrm{~m}^{2}$ & $\mathrm{c}_{A M}$ & $\mathbf{r}_{A M}$ & $\mathrm{c}_{H S}^{2}$ & $\mathrm{c}_{\mathrm{FS}}^{2}$ & $\mathrm{c}_{E C}$ & $\mathrm{~F}_{m}$ & $\mathrm{~h}_{A+M}^{2}$ & $\log \mathrm{L}$ \\
\hline 1 & 451 & 0.50 & & & & & & & & 0.50 & 0 \\
\hline $2 a$ & 417 & 0.30 & & & & 0.05 & 0.05 & & & 0.30 & 251 \\
\hline $2 \mathrm{~b}$ & 421 & 0.33 & & & & 0.00 & 0.05 & & & 0.33 & 298 \\
\hline $2 c$ & 414 & 0.28 & & & & 0.03 & 0.06 & & & 0.28 & 322 \\
\hline 3 & 429 & 0.31 & 0.07 & & & & & & & 0.34 & 232 \\
\hline 4 & 429 & 0.33 & 0.08 & -0.03 & -0.17 & & & & & 0.33 & 236 \\
\hline $5 a$ & 416 & 0.27 & 0.03 & & & 0.04 & 0.04 & & & 0.29 & 286 \\
\hline $5 \mathrm{~b}$ & 416 & 0.28 & 0.03 & & & 0.00 & 0.03 & & & 0.29 & 346 \\
\hline $5 \mathrm{c}$ & 413 & 0.26 & 0.02 & & & 0.02 & 0.04 & & & 0.27 & 352 \\
\hline $6 a$ & 414 & 0.33 & 0.04 & -0.06 & -0.54 & 0.05 & 0.05 & & & 0.26 & 311 \\
\hline $6 \mathrm{~b}$ & 416 & 0.33 & 0.05 & -0.05 & -0.38 & 0.00 & 0.04 & & & 0.28 & 361 \\
\hline $6 c$ & 412 & 0.32 & 0.04 & -0.06 & -0.54 & 0.03 & 0.06 & & & 0.25 & 376 \\
\hline 7 & 414 & 0.27 & & & & 0.06 & 0.06 & 0.06 & & 0.27 & 255 \\
\hline $8 a$ & 414 & 0.27 & & & & 0.06 & 0.06 & 0.04 & & 0.27 & 260 \\
\hline $8 \mathrm{~b}$ & 411 & 0.25 & & & & 0.04 & 0.06 & 0.04 & & 0.25 & 333 \\
\hline $8 c$ & 411 & 0.25 & & & & 0.04 & 0.07 & 0.04 & & 0.25 & 333 \\
\hline 9 & 413 & 0.24 & 0.03 & & & 0.04 & 0.04 & 0.04 & & 0.26 & 301 \\
\hline 10 & 409 & 0.29 & 0.06 & -0.08 & -0.64 & 0.06 & 0.06 & 0.06 & & 0.20 & 341 \\
\hline $11 a$ & 413 & 0.24 & 0.03 & & & 0.04 & 0.04 & 0.05 & & 0.26 & 301 \\
\hline $11 b$ & 411 & 0.24 & 0.02 & & & 0.03 & 0.05 & 0.03 & & 0.25 & 363 \\
\hline $11 \mathrm{c}$ & 410 & 0.22 & 0.03 & & & 0.02 & 0.05 & 0.05 & & 0.24 & 369 \\
\hline $12 \mathrm{a}$ & 409 & 0.29 & 0.07 & -0.09 & -0.64 & 0.06 & 0.06 & 0.08 & & 0.19 & 343 \\
\hline $12 \mathrm{~b}$ & 407 & 0.29 & 0.05 & -0.07 & -0.63 & $0 ; 04$ & 0.07 & 0.04 & & 0.21 & 399 \\
\hline $12 \mathrm{c}$ & 407 & 0.27 & 0.06 & -0.08 & -0.64 & 0.04 & 0.07 & 0.08 & & 0.18 & 409 \\
\hline 13 & 406 & 0.50 & & & & & & & 0.01 & 0.50 & 2 \\
\hline $14 \mathrm{a}$ & 413 & 0.26 & & & & 0.06 & 0.06 & & 0.06 & 0.26 & 266 \\
\hline $14 \mathrm{~b}$ & 418 & 0.30 & & & & 0.00 & 0.05 & & 0.04 & 0.30 & 306 \\
\hline $14 c$ & 410 & 0.24 & & & & 0.04 & 0.07 & & 0.07 & 0.24 & 337 \\
\hline 15 & 428 & 0.27 & 0.08 & & & & & & 0.05 & 0.31 & 245 \\
\hline 16 & 389 & 0.33 & 0.17 & -0.11 & -0.46 & & & & 0.09 & 0.25 & 262 \\
\hline $17 a$ & 413 & 0.23 & 0.03 & & & 0.04 & 0.04 & & 0.07 & 0.25 & 305 \\
\hline $17 \mathrm{~b}$ & 410 & 0.24 & 0.04 & & & 0.00 & 0.04 & & 0.06 & 0.26 & 363 \\
\hline $17 \mathrm{c}$ & 410 & 0.22 & 0.03 & & & 0.02 & 0.05 & & 0.08 & 0.24 & 371 \\
\hline $18 \mathrm{a}$ & 355 & 0.36 & 0.11 & -0.17 & -0.85 & 0.07 & 0.07 & & 0.12 & 0.16 & 365 \\
\hline $18 b$ & 359 & 0.33 & 0.13 & -0.17 & -0.80 & 0.00 & 0.05 & & 0.12 & 0.15 & 400 \\
\hline $18 \mathrm{c}$ & 349 & 0.36 & 0.13 & -0.20 & -0.92 & 0.05 & 0.08 & & 0.14 & 0.12 & 431 \\
\hline
\end{tabular}

${ }^{\text {a }} \sigma_{\mathrm{p}}^{2}$ : phenotypic variance in $\mathrm{kg}^{2} \times 10^{-4} ; h^{2}$ : direct heritability; $\mathrm{m}^{2}$ : maternal heritability; $c_{\mathrm{AM}}$ : direct-maternal genetic covariance as proportion of $\sigma_{\mathrm{P}}^{2} ; r_{\mathrm{AM}}$ : direct-maternal genetic correlation; $c^{2}$ : maternal environmental variance as proportion of $\sigma_{\mathrm{P}}^{2} ; r_{\mathrm{AM}}$ : direct-maternal environmental covariance as proportion of $\sigma_{\mathrm{P}}^{2} ; F_{\mathrm{m}}$ : Falconer parameter representing the regression on the dam's phenotype; $h_{\mathrm{A}+\mathrm{M}}^{2}$ : regression of direct plus maternal genotypes on the phenotype and $\log L$ : natural $\log$-likelihood deviated from model 1. 
Table IX. Estimates of genetic parameters and the relative (natural) log-likelihoods ${ }^{\mathrm{a}}$ under models 1-18 for juvenile body weight in population B.

\begin{tabular}{|c|c|c|c|c|c|c|c|c|c|c|c|}
\hline Model & $\sigma_{P}^{2}$ & $\mathrm{~h}^{2}$ & $\mathrm{~m}^{2}$ & $\mathrm{c}_{A M}$ & $\mathrm{r}_{A M}$ & $\mathrm{c}_{H S}^{2}$ & $\mathrm{c}_{\mathrm{FS}}^{2}$ & $c_{E C}$ & $\mathrm{~F}_{m}$ & $\mathrm{~h}_{A+M}^{2}$ & $\log \mathrm{L}$ \\
\hline 1 & 271 & 0.42 & & & & & & & & 0.42 & 0 \\
\hline $2 a$ & 255 & 0.24 & & & & 0.04 & 0.04 & & & 0.24 & 170 \\
\hline $2 b$ & 255 & 0.26 & & & & 0.00 & 0.04 & & & 0.26 & 256 \\
\hline $2 \mathrm{c}$ & 253 & 0.23 & & & & 0.02 & 0.05 & & & 0.23 & 265 \\
\hline 3 & 261 & 0.27 & 0.05 & & & & & & & 0.29 & 135 \\
\hline 4 & 261 & 0.28 & 0.05 & -0.01 & -0.11 & & & & & 0.29 & 136 \\
\hline $5 \mathrm{a}$ & 255 & 0.23 & 0.01 & & & 0.03 & 0.03 & & & 0.24 & 180 \\
\hline $5 b$ & 254 & 0.23 & 0.02 & & & 0.00 & 0.03 & & & 0.24 & 270 \\
\hline $5 c$ & 253 & 0.22 & 0.01 & & & 0.01 & 0.04 & & & 0.23 & 273 \\
\hline $6 a$ & 255 & 0.28 & 0.03 & -0.05 & -0.54 & 0.04 & 0.04 & & & 0.24 & 197 \\
\hline $6 \mathrm{~b}$ & 255 & 0.28 & 0.03 & -0.03 & -0.38 & 0.00 & 0.03 & & & 0.24 & 280 \\
\hline $6 c$ & 254 & 0.27 & 0.02 & -0.04 & -0.54 & 0.02 & 0.05 & & & 0.22 & 288 \\
\hline 7 & 253 & 0.21 & & & & 0.05 & 0.05 & 0.05 & & 0.23 & 191 \\
\hline $8 a$ & 253 & 0.21 & & & & 0.05 & 0.05 & 0.06 & & 0.22 & 192 \\
\hline $8 \mathrm{~b}$ & 252 & 0.21 & & & & 0.03 & 0.05 & 0.03 & & 0.21 & 280 \\
\hline $8 c$ & 252 & 0.20 & & & & 0.03 & 0.06 & 0.06 & & 0.21 & 291 \\
\hline 9 & 253 & 0.21 & 0.01 & & & 0.04 & 0.04 & 0.04 & & 0.22 & 203 \\
\hline 10 & 253 & $0 ; 25$ & 0.03 & -0.06 & -0.65 & 0.05 & 0.05 & 0.05 & & 0.19 & 230 \\
\hline $11 \mathrm{a}$ & 253 & 0.19 & 0.02 & & & 0.04 & 0.04 & 0.07 & & 0.22 & 209 \\
\hline $11 \mathrm{~b}$ & 252 & 0.20 & 0.01 & & & 0.02 & 0.05 & 0.02 & & 0.21 & 285 \\
\hline $11 \mathrm{c}$ & 252 & 0.18 & 0.02 & & & 0.02 & 0.05 & 0.07 & & 0.21 & 304 \\
\hline $12 \mathrm{a}$ & 252 & 0.24 & 0.05 & -0.07 & -0.64 & 0.05 & 0.05 & 0.09 & & 0.18 & 239 \\
\hline $12 \mathrm{~b}$ & 252 & 0.25 & 0.03 & -0.05 & -0.66 & 0.03 & 0.06 & 0.03 & & 0.19 & 309 \\
\hline $12 \mathrm{c}$ & 251 & 0.23 & 0.04 & -0.06 & -0.63 & 0.03 & 0.06 & 0.09 & & 0.17 & 330 \\
\hline 13 & 271 & 0.42 & & & & & & & 0.01 & 0.42 & 0 \\
\hline $14 \mathrm{a}$ & 253 & 0.22 & & & & 0.04 & 0.04 & & 0.06 & 0.22 & 189 \\
\hline $14 \mathrm{~b}$ & 254 & 0.24 & & & & 0.00 & 0.04 & & 0.06 & 0.24 & 273 \\
\hline $14 \mathrm{c}$ & 252 & 0.21 & & & & 0.02 & 0.05 & & 0.07 & 0.21 & 287 \\
\hline 15 & 259 & 0.24 & 0.05 & & & & & & 0.06 & 0.27 & 155 \\
\hline 16 & 249 & 0.28 & 0.08 & -0.05 & -0.31 & & & & 0.08 & 0.25 & 163 \\
\hline $17 a$ & 254 & 0.22 & 0.02 & & & 0.03 & 0.03 & & 0.07 & 0.23 & 203 \\
\hline $17 \mathrm{~b}$ & 253 & 0.21 & 0.02 & & & 0.00 & 0.03 & & 0.07 & 0.22 & 294 \\
\hline $17 \mathrm{c}$ & 252 & 0.20 & 0.01 & & & 0.01 & 0.04 & & 0.07 & 0.21 & 297 \\
\hline $18 \mathrm{a}$ & 232 & 0.30 & 0.06 & -0.10 & -0.80 & 0.05 & 0.05 & & 0.11 & 0.17 & 239 \\
\hline $18 \mathrm{~b}$ & 237 & 0.28 & $0 ; 05$ & -0.07 & -0.60 & 0.00 & 0.04 & & 0.10 & 0.20 & 316 \\
\hline $18 \mathrm{c}$ & 232 & 0.29 & 0.06 & -0.10 & -0.81 & 0.03 & 0.06 & & 0.11 & 0.16 & 331 \\
\hline
\end{tabular}

${ }^{\text {a }}$ see table VIII for abbreviations.

$m^{2}$ estimates in model 5 a decreased substantially for strain A (from 0.07 to 0.03 ) and for strain B (from 0.05 to 0.01); and thus the maternal variance seemed to be more of a (permanent) environmental than genetic origin. Estimating $\sigma_{\mathrm{AM}}$ in addition to model 5 (model 6) showed a similar pattern for both strains in terms of the reduction in $m^{2}$ compared to model 4 . Most noticeable, however, was that 
this smaller $m^{2}$ parameter was accompanied by a much more negative $c_{\mathrm{AM}}$ and consequently $r_{\mathrm{AM}}$ relative to model 4 .

Likelihoods increased considerably by adopting $c_{\mathrm{EC}}$. All the $c_{\mathrm{EC}}$ estimates were positive and consequently the estimates of $r_{\mathrm{AM}}$ tended to be more negative and heritability estimates dropped somewhat. For the models $12 \mathrm{a}$ and $12 \mathrm{c}$ the $\mathrm{m}^{2}$ estimate increased by a factor of 1.5 to 2 (from $0.04(0.04)$ to $0.07(0.06)$ in population A and from $0.03(0.02)$ to 0.05 (0.04) in population B). Assuming a zero $c_{\mathrm{AM}}$ and a non-zero $c_{\mathrm{EC}}$ (model 11) fitted the data of population $\mathrm{B}$ better than the reverse assumption, a non-zero $c_{\mathrm{AM}}$ and a zero $c_{\mathrm{EC}}$ (model 6). This was not the case for population A. However, the highest likelihood for both populations was attained by assuming both these covariances to be non-zero (in model 12).

All the $F_{\mathrm{m}}$ values were positive (in models $13-18$ ) as were the $c_{\mathrm{EC}}$ estimates in models 7-12. The models without a $c^{2}$-effect (models 13, 15 and 16) did not fit as well as their counterparts fitting $c_{\mathrm{EC}}$ (models 7,9 and 10, respectively). The $F_{\mathrm{m}}$ estimates were generally similar for both populations. The improvements in likelihood relative to the models $7-12$ were greater for population $\mathrm{A}$. The $F_{\mathrm{m}}$ estimates for model $14 \mathrm{~b}$ were similar to the estimates based on multiple regression of the analysis of variance components (table VII). Generally, $m^{2}$ and $c_{\text {AM }}$ estimates increased somewhat and led to more negative $r_{\mathrm{AM}}$ values compared to the models including $c_{\mathrm{EC}}$.

\section{Estimation of sampling variation of $c_{\mathrm{AM}}$ and $c_{\mathrm{EC}}$}

Approximate profile likelihood and (derived) sampling variances for $c_{\mathrm{AM}}$ (in models $6 \mathrm{c}$ and $12 \mathrm{c}$ ) and $c_{\mathrm{EC}}$ (in model $12 \mathrm{c}$ ) were investigated to obtain a better insight into the accuracy of $c_{\mathrm{AM}}$ in model $6 \mathrm{c}$ (assuming zero $\sigma_{\mathrm{EC}}$ ) compared to the accuracy that could be attained when the potentially highly confounded components $c_{\mathrm{AM}}$ and $c_{\mathrm{EC}}$ (Meyer, 1992b) were estimated together (model 12c), using the present sizeable data sets.

Figure 1 depicts the quartic Taylor polynomial fitted to seven points of the profile likelihood for $c_{\mathrm{AM}}$ (with $R^{2}=100 \%$ ). The resulting approximate profile likelihood shows that $c_{\mathrm{AM}}$ is highly unlikely to be positive for both strains.

The approximate profile likelihood curvatures for $c_{\mathrm{AM}}$ and $C_{\mathrm{EC}}$ (both quartic as well with $R^{2}=100 \%$ ) in model $12 \mathrm{c}$ are shown in figure $2 \mathrm{a}$ and b, respectively. Once again, profiles show a similar pattern for both strains and also the profiles for $c_{\mathrm{AM}}$ and $c_{\mathrm{EC}}$ act fairly similarly to the images (with opposite sign for the values) of $c_{\mathrm{EC}}$ and $c_{\mathrm{AM}}$, respectively, which pointed towards the presence of a high negative sampling covariation between these components. The figures illustrate the low likelihood of a positive $c_{\mathrm{AM}}$ on the one hand and the very low likelihood of a negative $c_{\mathrm{EC}}$ on the other hand.

The sampling errors approximated from the above profile likelihood curves are exhibited in table X. Generally, the direct-maternal covariance components were accurately estimated for both strains, with the sampling error of $c_{\mathrm{EC}}$ being roughly half the size of the approximation for $c_{\mathrm{AM}}$. The accuracy of the $c_{\mathrm{AM}}$ estimates for models $6 \mathrm{c}$ and $12 \mathrm{c}$ were similar, hence the sampling correlation of $c_{\mathrm{AM}}$ with $c_{\mathrm{EC}}$ (in model 12c) did not hinder much the precise estimation of these components for the present data. Approximate sampling errors were also similar for both strains, 


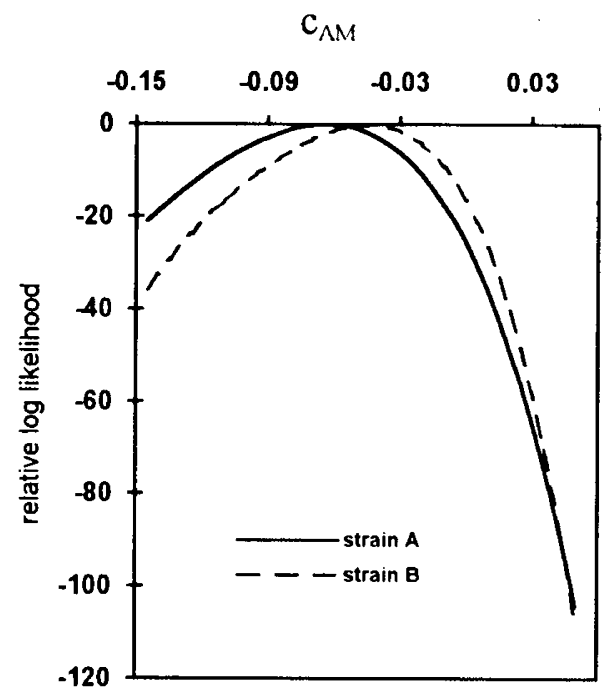

Fig 1. The approximate profile log-likelihood for the direct-maternal genetic covariance component expressed as proportion of the phenotypic variance $\left(c_{\mathrm{AM}}\right)$ in model $6 \mathrm{c}$.
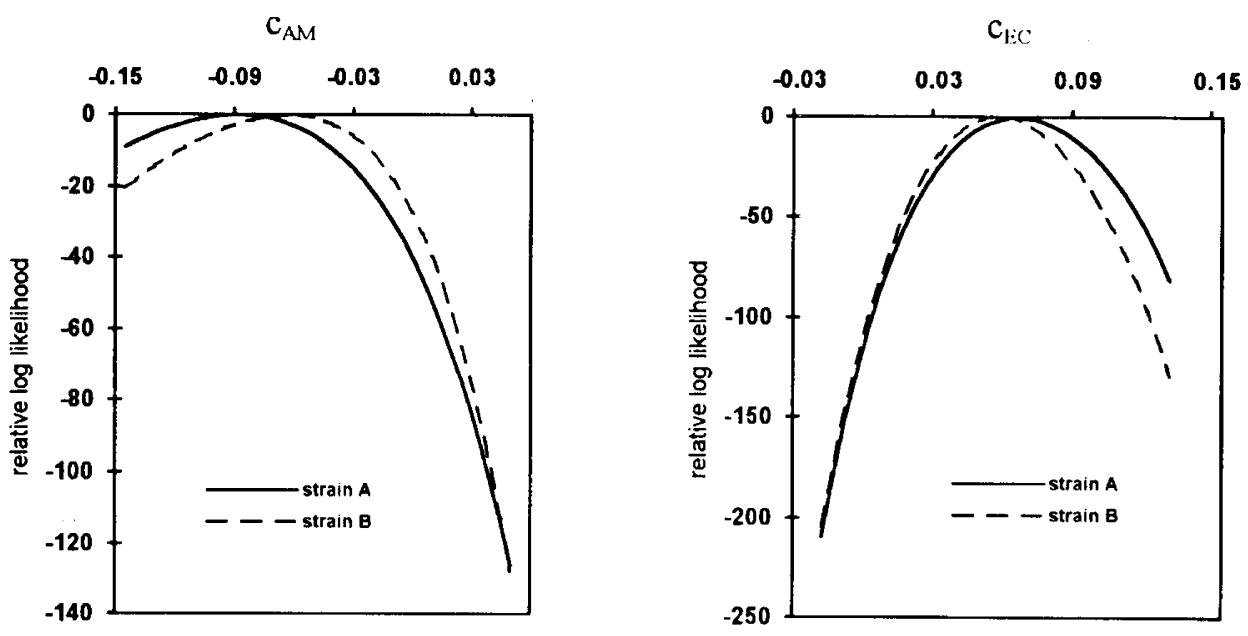

Fig 2. The approximate profile log-likelihoods for (a) the direct-maternal genetic covariance component $\left(c_{\mathrm{AM}}\right)$ and $(\mathrm{b})$ the direct-maternal environmental covariance component $\left(c_{\mathrm{EC}}\right)$ both expressed as proportion of the phenotypic variance in model 12c. 
which was illustrated by the similar curvatures of the profile likelihoods for strains $\mathrm{A}$ and $\mathrm{B}$.

Table X. Asymptotic sampling errors for the direct-maternal genetic covariance component $\left(c_{\mathrm{AM}}\right)$ (in models $6 \mathrm{c}$ and 12c) and for the direct-maternal environmental covariance component $\left(c_{\mathrm{EC}}\right)$ (in model $12 \mathrm{c}$ ) both expressed as proportion of the phenotypic variance.

\begin{tabular}{lrcc}
\hline Strain & Model & $c_{\mathrm{AM}}$ & $c_{\mathrm{EC}}$ \\
\hline $\mathrm{A}$ & $6 \mathrm{c}$ & 0.018 & - \\
& $12 \mathrm{c}$ & 0.019 & 0.009 \\
$\mathrm{~B}$ & $6 \mathrm{c}$ & 0.016 & - \\
& $12 \mathrm{c}$ & 0.018 & 0.008 \\
\hline
\end{tabular}

\section{DISCUSSION}

\section{Sex-linkage}

The segregation of sex-linked genes affecting JBWT was found to be small, which agrees with results summarised by Chambers (1990). Owing to their hemizygous form these genes are likely to be driven towards fixation, especially in meat-type poultry with a long and extensive selection history for growth traits. The genetic correlation between male and female JBWT performance was just significantly different from unity, but this could easily be attributable to endocrine differences between both sexes.

\section{Analysis of variance}

The estimates of $F_{\mathrm{m}}$, found while equating the (co)variance components to their expectations and minimising MSE, were small (0.03 and 0.07) and similar to the values $(0.04$ and 0.06$)$ found for its equivalent in a mixed model setting, model $14 \mathrm{~b}$. The conventional $h^{2}$ estimates were, however, substantially lower ( 0.21 versus 0.30 and 0.19 versus 0.24 for the populations $\mathrm{A}$ and $\mathrm{B}$, respectively). The difference in estimates was larger for population $\mathrm{A}$. The data on population A represented six generations (three more than population B) and hence the numerator relationship matrix accounted for more selection in this longer time period.

\section{Maternal effects estimation in a mixed model setting}

It was shown that inclusion of a maternal permanent environmental effect provided a much better fit to the data (over model 1) and that inclusion of any more effects, although statistically significant, gave relatively a much smaller additional increase in $\log L$ (over model 2). This was reflected by the direct heritability estimates, which fluctuated within a rather narrow range for models 2-18 (except for model 13) compared to the heritability estimates for model 1. Consequently, the smaller additional increases in $\log L$ (over model 2) originated primarily from a 'reshuffe' 
of the maternal variance over environmental and genetic maternal (co)variances, although some cross-substitution of the direct additive genetic variance and hence the direct heritability with the direct-maternal genetic covariance, in particular, was likely to occur (Thompson, 1976; Meyer, 1992b). Dominance might have some effect on estimates of maternal effects, although dominance was found to be of little importance in broiler body weight (Koerhuis et al, 1997).

REML combines information on various collateral relatives and various offspringparent regressions in order to obtain one efficiently pooled estimate for $h^{2}$ with minimum variance (Thompson, 1977; Hill, 1988). The large reduction in the $h^{2}$ estimate in model 2 compared to model 1 , accompanied by relatively small $c^{2}$ estimates, suggested a high weighting of the between dam family $h^{2}$ estimate, relative to the between sire family $h^{2}$ estimate. This might have been expected with such a large number, on average, of large dam families in the data (table II), leading to very accurate estimates on between dam family variance. A lower weighting of dam family information is expected for domesticated species in general and for beef cattle in particular, where dam families are much smaller (eg, Meyer, 1992a). The $h^{2}$ estimates in model 2 should be expected to be closer to the HendersonIII sire component $h^{2}$ estimates. Chambers (1990) pooled 53 sire component $h^{2}$ estimates from 23 studies resulting in an average value of 0.41 . The present smaller $h^{2}$ estimates might be explained by the much longer and more extensive selection period the present broiler populations have undergone in comparison to the populations used in many experiments, bearing in mind that the vast majority of these studies was conducted two to three decades ago. The smaller variance for strain B might, beside genetic strain differences, be due to the lesser extent of correction for reduction in variance caused by selection as only three generations were available for this strain compared to six generations for strain A. Furthermore, Chambers' (1990) summarised estimates were often based on weights at older ages $(8,9$ or 10 weeks). It is not uncommon for heritabilities to increase with age of weight owing to diminishing maternal influences.

Allowing for $\sigma_{\mathrm{AM}}$, resulted in a value of $r_{\mathrm{AM}}$ that was considerably negative in model 6. This was somewhat surprising since we expected a positive genetic correlation between JBWT and egg weight (Kinney, 1969; Koerhuis and McKay, 1996), which is believed to increase the offspring's JBWT. Fitting both $\sigma_{\mathrm{AM}}$ and $\sigma_{\mathrm{EC}}$ (model 12), to account for possible downward bias of $\sigma_{\mathrm{AM}}$ (Koch, 1972; Meyer, 1992b), resulted in slightly more negative $r_{\mathrm{AM}}$ estimates owing to positive estimates of $\sigma_{\mathrm{EC}}$. Cantet et al (1988) also obtained large negative estimates of $\sigma_{\mathrm{AM}}$ accompanied by positive estimates of $\sigma_{\mathrm{EC}}$ for growth traits in beef cattle. However, Cantet et al (1988) found negative estimates for $F_{\mathrm{m}}$ (in the range -0.15 to -0.25 ), whereas our estimates of $F_{\mathrm{m}}$ were positive just like $\sigma_{\mathrm{EC}}$ estimates and led to even more negative $r_{\mathrm{AM}}$ estimates. Cantet et al (1988) had a small data set and used conventional methods, equating separately estimated covariances between relatives to their expectations and solving the resulting system of linear equations. This ignores the fact that the same animal might have contributed to different types of covariances and that different observational components might have different sampling variances, ie, combining information in a non-optimal way (Cantet et al, 1988; Meyer, 1992b). 
For our JBWT data, the genetic variance of maternal origin could, for the greater part, relate to egg (shell) quality rather than egg size, which could explain the negative sign of $\sigma_{\mathrm{AM}}$. Koerhuis et al (1997), following suggestions by Lande and Kirkpatrick (1990), fitted individual maternal pathways related to the egg as covariates in an offspring-parental regression model, to investigate their importance in causing maternal variation in JBWT. Those results implied a negative partial maternal effect of egg weight loss between the start and the 18th day of incubation, and are in agreement with Robinson et al (1993) who reported a negative relationship between body weight and egg (shell) quality, an inferior quality giving rise to a greater loss of weight. However, this negative partial effect was offset by a positive partial maternal effect of egg weight at the 18th day of incubation, and hence the aggregate maternal effect on JBWT was found to be small (Koerhuis et al, 1997).

A negative $\sigma_{\mathrm{AM}}$ would decrease the efficiency of phenotypic selection for JBWT as expressed by the low $h_{\mathrm{A}+\mathrm{M}}^{2}$ estimates for the models 12 and 18 with overall superior $\log L$. Selection on maternal breeding values for JBWT may, however, not be very effective owing to the low maternal heritability. Moreover, it might not be the preferable approach since egg (shell) quality characteristics can readily be selected for directly with higher accuracy and predictability (Koerhuis et al, 1997) and less delay, because the expression of the maternal effect, although occurring later in life, would not lag a generation behind the direct effect as is normally the case (Willham, 1980). Nevertheless, the presented amalgamation of Falconer and Willham models in a mixed model setting might offer attractive alternatives to Meyer's (1989) models for, eg, beef cattle as was illustrated by results based on simulated data (table VII).

Meyer (1992b) studied the sampling behaviour of REML estimates of (co)variance components due to additive genetic and environmental maternal effects. She showed that sampling correlations between estimates were high and that sizeable data sets are required to allow reasonably accurate estimates to be obtained. Results in the present study, using large data sets, illustrated the possibility of good sampling properties for both the genetic and environmental direct-maternal covariance components. Hence, these poultry data sets might also increase the scope for the application of more detailed models, eg, estimating dominance variance and variance due to new mutation in addition to genetic and environmental maternal effects, yet providing sufficient contrast for the often highly correlated genetic parameters involved, to be estimated precisely. More research is needed, however, with regard to the practicalities of such detailed maternal effects (and other) models for use in genetic evaluation methods performed by breeders.

\section{The effect of more detailed fixed effect structures}

Robinson $(1994,1996)$ showed that additional variation $(\mathrm{eg}$, sire $\times$ year) unaccounted for in the model affected estimates of maternal effects. Differences in results from Mackinnon et al (1991) and Meyer (1992a) for the same data suggested sensitivity of maternal effects to different fixed effects models. In our data different parental flocks of different ages and farms contributed offspring to one hatch week. The age difference was accounted for in the model, but more specific maternal environmental flock effects were ignored. The parental flocks contributing to every hatch 
Table XI. Estimates of genetic parameters and the relative (natural) log-likelihoods under the most comprehensive models using a more detailed fixed effect structure for juvenile body weight on both populations ${ }^{\mathrm{a}}$.

\begin{tabular}{lccccccccccr}
\hline Model & $\sigma_{P}^{2}$ & $\mathrm{~h}^{2}$ & $\mathrm{~m}^{2}$ & $\mathrm{c}_{A M}$ & $\mathrm{r}_{A M}$ & $\mathrm{c}_{H S}^{2}$ & $\mathrm{c}_{\mathrm{FS}}^{2}$ & $\mathrm{c}_{E C}$ & $\mathrm{~F}_{m}$ & $\mathrm{~h}_{A+M}^{2}$ & $\log \mathrm{L}$ \\
\hline $5 \mathrm{c}$ & 373 & 0.20 & 0.02 & & & 0.02 & 0.05 & & & 0.21 & 0 \\
$6 \mathrm{c}$ & 373 & 0.20 & 0.02 & 0.00 & 0.04 & 0.02 & 0.05 & & & 0.21 & 0 \\
$11 \mathrm{c}$ & 370 & 0.15 & 0.03 & & & 0.04 & 0.06 & 0.09 & & 0.17 & 47 \\
$12 \mathrm{c}$ & 369 & 0.15 & 0.04 & -0.02 & -0.21 & 0.04 & 0.07 & 0.10 & & 0.14 & 49 \\
$17 \mathrm{c}$ & 375 & 0.17 & 0.03 & & & 0.03 & 0.05 & & 0.08 & 0.19 & 70 \\
$18 \mathrm{c}$ & 378 & 0.17 & 0.04 & -0.02 & -0.18 & 0.03 & 0.06 & & 0.14 & 0.16 & 98 \\
$5 \mathrm{c}$ & 237 & 0.21 & 0.01 & & & 0.02 & 0.04 & & & 0.22 & 0 \\
$6 \mathrm{c}$ & 237 & 0.22 & 0.01 & -0.01 & -0.17 & 0.02 & 0.04 & & & 0.21 & 1 \\
$11 \mathrm{c}$ & 235 & 0.15 & 0.01 & & & 0.03 & 0.06 & 0.10 & & 0.16 & 59 \\
$12 \mathrm{c}$ & 235 & 0.16 & 0.02 & -0.02 & -0.39 & 0.04 & 0.06 & 0.11 & & 0.14 & 64 \\
$17 \mathrm{c}$ & 233 & 0.15 & 0.02 & & & 0.02 & 0.05 & & 0.20 & 0.16 & 68 \\
$18 \mathrm{c}$ & 233 & 0.17 & 0.03 & -0.02 & -0.33 & 0.02 & 0.05 & & 0.18 & 0.16 & 76 \\
\hline
\end{tabular}

a See table VIII for abbreviations.

were identified. The effect of flock nested within hatch on the genetic parameters in models 1 and 2 was small (not presented). The effect on the genetic parameters for the more comprehensive models $(5 c, 6 c, 11 c, 12 c, 17 c$ and 18c) was investigated for both populations. The phenotypic and direct and maternal genetic variances were reduced considerably and were accompanied by $r_{\mathrm{AM}}$ estimates much closer to zero (see table XI). The $h^{2}$ estimates were now very similar to the estimates of $h_{\mathrm{A}+\mathrm{M}}^{2}$. This limited importance of maternal effects exerting a non-Mendelian influence on JBWT is in closer agreement with the results obtained by Koerhuis et al (1997). The choice of the fixed effects model appears to be paramount for detailed maternal effects models, but the increase in computing time (four-fold increase per likelihood evaluation for the present data) might often prevent more refined fixed effect structures to be occupied.

\section{ACKNOWLEDGEMENTS}

We acknowledge the help of referees in turning the nebulous description of the method into something more intelligible. RT acknowledges the support of MAFF in this work. IACR-Rothamsted receives grant-aided support from the Biotechnology and Biological Sciences Research Council.

\section{REFERENCES}

Cantet RJC, Kress DD, Anderson DC, Doornbos DE, Burfening PJ, Blackwell RL (1988) Direct and maternal variances and covariances and maternal phenotypic effects on preweaning growth of beef cattle. J Anim Sci 66, 648-660

Chambers JR (1990) Genetics of growth and meat production in chickens. In: Poultry Breeding and Genetics (RD Crawford, ed), Elsevier, ch 25, 599-643 
Falconer DS (1965) Maternal effects and selection response. In: Genetics today (SJ Geerts, ed), Pergamon Press, New York

George A, Liu JWH (1980) Computer Solutions of Large Sparse Positive Definite Systems. Prentice-Hall, Englewood Cliffs, New York

Henderson CR (1976) A simple method for computing the inverse of a numerator relationship matrix used for prediction of breeding values. Biometrics 32,69

Hill WG (1988) Considerations in the design of animal breeding experiments. In: Proc. Symp Adv Stat Meth Genet Improv Livest (K Hammond, D Gianola, eds), Springer Verlag, Heidelberg

Kinney TB Jr (1969) A summary of reported estimates of heritabilities and of genetic and phenotypic correlations for traits of chickens. Agric Handbook No 363, Agric Res Service, US Dept Agric

Koch RM (1972) The role of maternal effects in animal breeding. VI. Maternal effects in beef cattle. J Anim Sci 35, 1316-1323

Koerhuis ANM, McKay JC (1996) Restricted maximum likelihood estimation of genetic parameters for egg production traits in relation to juvenile body weight in broiler chickens. Livest Prod Sci 46, 117-127

Koerhuis ANM, McKay JC, Hill WG, Thompson R (1997) A genetic analysis of egg quality traits and their maternal influence on offspring-parental regressions of juvenile body weight performance in broiler chickens. Livest Prod Sci (In press)

Lande R, Kirkpatrick M (1990) Selection response in traits with maternal inheritance. Genet Res 55, 189-197

Mackinnon MJ, Meyer K, Hetzel DJS (1991) Genetic variation and covariation for growth, parasite resistance and heat tolerance in tropical cattle. Livest Prod Sci 27, 105-122

Meyer K (1989) Restricted maximum likelihood to estimate variance components for animal models with several random effects using a derivative-free algorithm. Genet Sel Evol 21, 317-340

Meyer K (1992a) Variance components due to direct and maternal effects for growth traits of Australian beef cattle. Livest Prod Sci 31, 179-204

Meyer K (1992b) Bias and sampling covariances of estimates of variance components due to maternal effects. Genet Sel Evol 24, 487-509

Mohiuddin G (1993) Estimates of genetic and phenotypic parameters of some performance traits in beef cattle. Anim Breed Abstr 61, 495-522

Nelder JA, Mead R (1965) A simplex method for function minimization. Computer $J 7$, $147-151$

Robinson DL (1994) Models which might explain negative correlations between direct and maternal genetic effects. In: Proc 5th World Congr Genet Appl Livest Prod Guelph Canada.

Robinson DL (1996) Estimation and interpretation of direct and maternal genetic parameters for weights of Australian Angus cattle. Livest Prod Sci 45, 1-11

Robinson FE, Wilson JL, Yu MW, Fasenko GM, Hardin RT (1993) The relationship between body weight and reproductive efficiency in meat-type chickens. Poultry Sci 72, 912-922

Smith SP, Graser H-U (1986) Estimating variance components in a class of mixed models by restricted maximum likelihood. J Dairy Sci 69 , 1156-1165

Thompson R (1976) The estimation of maternal genetic variances. Biometrics 32, 903-917

Thompson R (1977) The estimation of heritability with unbalanced data. II. Data available on more than two generations. Biometrics 33, 497-504

Thompson R, Crump RE, Juga J, Visscher PM (1995) Estimating variances and covariances for bivariate animal models using scaling and transformation. Genet Sel Evol 27, $33-42$ 
Willham RL (1963) The covariance between relatives for characters composed of components contributed by related individuals. Biometrics 19, 18-27

Willham RL (1980) Problems in estimating maternal effects. Livest Prod Sci 7, 405-418

\section{APPENDIX}

\section{The (direct) Falconer model}

Falconer (1965) suggested that a model for the phenotype of an individual, $y$, might be expressed as

$$
y=A+F_{\mathrm{m}} y^{\prime}+D+C+E
$$

where $A$ is the individual's breeding value; $F_{\mathrm{m}} y^{\prime}$ is the maternal effect as linear function $F_{\mathrm{m}}$ of the mother's phenotype $y^{\prime} ; D$ is the individual's dominance deviation; $C$ is the effect of environmental factors common to full sibs that are not included in the maternal effect; and $E$ represents all other environmental effects. The coefficient $F_{\mathrm{m}}$ is a partial regression coefficient relating daughters' to mothers' phenotypic values in the absence of genetic variation among the mothers. When $D$, $C$ and $E$ are ignored and mother's phenotype is represented by $y^{\prime}=A^{\prime}+F_{\mathrm{m}} y^{\prime \prime}$, the expectation of the dam-offspring covariance is

$$
\begin{aligned}
\operatorname{cov}\left(y, y^{\prime}\right) & =\operatorname{cov}\left(A, y^{\prime}\right)+F_{\mathrm{m}} \operatorname{var}\left(y^{\prime}\right) \\
& =\operatorname{cov}\left(A, A^{\prime}\right)+F_{\mathrm{m}} \operatorname{cov}\left(A, y^{\prime \prime}\right)+F_{\mathrm{m}} \sigma_{\mathrm{P}}^{2} \\
& =\frac{1}{2} \sigma_{\mathrm{A}}^{2}+F_{\mathrm{m}} \operatorname{cov}\left(A, y^{\prime \prime}\right)+F_{\mathrm{m}} \sigma_{\mathrm{P}}^{2}
\end{aligned}
$$

where

$$
\begin{aligned}
F_{\mathrm{m}} \operatorname{cov}\left(A, y^{\prime \prime}\right) & =F_{\mathrm{m}}\left(\operatorname{cov}\left(A, A^{\prime \prime}\right)+F_{\mathrm{m}} \operatorname{cov}\left(A, y^{\prime \prime \prime}\right)\right) \\
& =F_{\mathrm{m}}\left(\operatorname{cov}\left(A, A^{\prime \prime}\right)+F_{\mathrm{m}}\left(\operatorname{cov}\left(A, A^{\prime \prime \prime}\right)+\operatorname{cov}\left(A, y^{\prime \prime \prime \prime}\right)\right)\right) \\
& =F_{\mathrm{m}} \operatorname{cov}\left(A, A^{\prime \prime}\right)+F_{\mathrm{m}}^{2} \operatorname{cov}\left(A, A^{\prime \prime \prime}\right)+F_{\mathrm{m}}^{3} \operatorname{cov}\left(A, A^{\prime \prime \prime \prime}\right)+\ldots \text { etc } \\
& =\left(\frac{1}{4} F_{\mathrm{m}}+\frac{1}{8} F_{\mathrm{m}}^{2}+\frac{1}{16} F_{\mathrm{m}}^{3}+\ldots\right) \sigma_{\mathrm{A}}^{2}
\end{aligned}
$$

which is a geometric series with common ratio $1 / 2 F_{\mathrm{m}}$ that can be summarised as $\frac{F_{\mathrm{m}}}{2\left(2-F_{\mathrm{m}}\right)} \sigma_{\mathrm{A}}^{2}$ and hence $\operatorname{cov}\left(y, y^{\prime}\right)=\frac{1}{2} \sigma_{A}^{2}+\frac{F_{\mathrm{m}}}{2\left(2-F_{\mathrm{m}}\right)} \sigma_{\mathrm{A}}^{2}+F_{\mathrm{m}} \sigma_{\mathrm{P}}^{2}$ (Falconer, 1965; Thompson, 1976). The variance of $y$ in model [A1] (ignoring dominance) can be described as

$$
\operatorname{var}(y)=\sigma_{\mathrm{P}}^{2}=\sigma_{\mathrm{A}}^{2}+2 F_{\mathrm{m}} \operatorname{cov}\left(A, y^{\prime}\right)+F_{\mathrm{m}}^{2} \operatorname{var}\left(y^{\prime}\right)+\sigma_{\mathrm{C}}^{2}+\sigma_{\mathrm{E}}^{2}
$$


where

$$
\begin{aligned}
\operatorname{cov}\left(A, y^{\prime}\right) & =\operatorname{cov}\left(A, A^{\prime}\right)+F_{\mathrm{m}} \operatorname{cov}\left(A, A^{\prime \prime}\right)+F_{\mathrm{m}}^{2} \operatorname{cov}\left(A, A^{\prime \prime \prime}\right)+\ldots \text { etc } \\
& =\left(\frac{1}{2}+\frac{1}{4} F_{\mathrm{m}}+\frac{1}{8} F_{\mathrm{m}}^{2}+\ldots \text { etc }\right) \sigma_{\mathrm{A}}^{2} \\
& =\frac{1 / 2 \sigma_{\mathrm{A}}^{2}}{1-F_{\mathrm{m}} / 2}=\frac{\sigma_{\mathrm{A}}^{2}}{2-F_{\mathrm{m}}}
\end{aligned}
$$

and thus

$$
\begin{aligned}
\sigma_{\mathrm{P}}^{2} & =\sigma_{\mathrm{A}}^{2}+\frac{2 F_{\mathrm{m}}}{2-F_{\mathrm{m}}} \sigma_{\mathrm{A}}^{2}+F_{\mathrm{m}}^{2} \sigma_{\mathrm{P}}^{2}+\sigma_{\mathrm{C}}^{2}+\sigma_{\mathrm{E}}^{2} \\
\left(1-F_{\mathrm{m}}^{2}\right) \sigma_{\mathrm{P}}^{2} & =\sigma_{\mathrm{A}}^{2}+\frac{2 F_{\mathrm{m}}}{2-F_{\mathrm{m}}} \sigma_{\mathrm{A}}^{2}+\sigma_{\mathrm{C}}^{2}+\sigma_{\mathrm{E}}^{2} \\
\sigma_{\mathrm{P}}^{2} & =\left[\sigma_{\mathrm{A}}^{2}+\frac{2 F_{\mathrm{m}}}{2-F_{\mathrm{m}}} \sigma_{\mathrm{A}}^{2}+\sigma_{\mathrm{C}}^{2}+\sigma_{\mathrm{E}}^{2}\right] /\left(1-F_{\mathrm{m}}^{2}\right)
\end{aligned}
$$

In a mixed model setting a complication arises when considering estimation of the Falconer parameter $\left(F_{\mathrm{m}}\right)$. This is due to the offspring of base animals being uncorrected for $F_{\mathrm{m}}\left(\mathbf{y}_{\mathrm{P}}-\mathbf{X}_{\mathrm{P}} \mathbf{b}\right)$ since their dams' observations are unknown, which creates extra noise among these individuals. These animals' residual variances need to be scaled to produce constant variance across all individuals. The residual variance of those individuals is

$$
\begin{aligned}
\sigma_{\mathrm{E} *}^{2} & =\sigma_{\mathrm{P}}^{2}-\sigma_{\mathrm{A}}^{2}-\sigma_{\mathrm{C}}^{2} \\
& =\left[\sigma_{\mathrm{A}}^{2}+\frac{2 F_{\mathrm{m}}}{2-F_{\mathrm{m}}} \sigma_{\mathrm{A}}^{2}+\sigma_{\mathrm{C}}^{2}+\sigma_{\mathrm{E}}^{2}-\left(1-F_{\mathrm{m}}^{2}\right) \sigma_{\mathrm{A}}^{2}-\left(1-F_{\mathrm{m}}^{2}\right) \sigma_{\mathrm{C}}^{2}\right] /\left(1-F_{\mathrm{m}}^{2}\right) \\
& =\left[F_{\mathrm{m}}^{2} \sigma_{\mathrm{A}}^{2}+\frac{2 F_{\mathrm{m}}}{2-F_{\mathrm{m}}} \sigma_{\mathrm{A}}^{2}+F_{\mathrm{m}}^{2} \sigma_{\mathrm{C}}^{2}+\sigma_{\mathrm{E}}^{2}\right] /\left(1-F_{\mathrm{m}}^{2}\right) \\
& =\left[\left\{\left(F_{\mathrm{m}}^{2}+\frac{2 F_{\mathrm{m}}}{2-F_{\mathrm{m}}}\right) \frac{\sigma_{\mathrm{A}}^{2}}{\sigma_{\mathrm{E}}^{2}}+F_{\mathrm{m}}^{2} \frac{\sigma_{\mathrm{C}}^{2}}{\sigma_{\mathrm{E}}^{2}}+1\right\} /\left(1-F_{\mathrm{m}}^{2}\right)\right] \sigma_{\mathrm{E}}^{2}
\end{aligned}
$$

from which the scaling factor $\left(s_{\mathrm{F}}\right)$ emerges as a function of the variance components and the parameter $F_{\mathrm{m}}$ :

$$
s_{\mathrm{F}}=\left[\left(F_{\mathrm{m}}^{2}+\frac{2 F_{\mathrm{m}}}{2-F_{\mathrm{m}}}\right) \frac{\sigma_{\mathrm{A}}^{2}}{\sigma_{\mathrm{E}}^{2}}+F_{\mathrm{m}}^{2} \frac{\sigma_{\mathrm{C}}^{2}}{\sigma_{\mathrm{E}}^{2}}+1\right] /\left(1-F_{\mathrm{m}}^{2}\right)
$$

Without $C$ in model 4 the term $F_{\mathrm{m}}^{2} \sigma_{\mathrm{C}}^{2} / \sigma_{\mathrm{E}}^{2}$ cancels out.

This argument assumes that the only adjustment necessary is because the phenotypic variance changes. However the genetic structure is slightly changed. The additive genetic variance associated with a value uncorrected for a maternal phenotypic variance, $y_{\mathrm{uc}}$, is $c_{\mathrm{AC}} \sigma_{\mathrm{A}}^{2}$ with $c_{\mathrm{AC}}=\left(1+2 F_{\mathrm{m}} /\left(2-F_{\mathrm{m}}\right)\right) /\left(1-F_{\mathrm{m}}^{2}\right)$, and the genetic covariance of $y_{\mathrm{uc}}$ with a corrected $t$ th generation descendant is $c_{\mathrm{AC}} \sigma_{\mathrm{A}}^{2}$ with $c_{\mathrm{AC}}=\left[2 /\left(2-F_{\mathrm{m}}\right)\right] 2^{-t}$. This can be simply incorporated in the linear model using $y=A+F_{\mathrm{m}} A^{\prime \mathrm{c}}+D+C+E$ where $A^{\prime \mathrm{c}}$ is an accumulated additive value 
with $A^{\prime c}=A^{\prime}+F_{\mathrm{m}} A^{\prime \prime}+F_{\mathrm{m}}^{2} A^{\prime \prime \prime}+\ldots$ etc, with var $A^{\prime \mathrm{c}}=c_{\mathrm{AC}} \sigma_{\mathrm{A}}^{2}$ and the covariance between $A^{\prime \mathrm{c}}$ and $A^{\prime}$ is $c_{\mathrm{AC}} \sigma_{\mathrm{A}}^{2}$. Terms in the relationship matrix $A^{*}$, relating $A^{\prime c}$ and other genetic values, can be constructed using the usual rules of relationship matrices. The inverse matrix can be constructed using rules similar to Henderson (1976). The diagonal term for base dams is $c_{\mathrm{AC}}$. The contribution of each individual $i$, with known parents to $A^{t-1}$ is a matrix $\left.\left(-x_{\mathrm{s} i},\right) x_{\mathrm{d} i}, l\right)^{\prime} m_{i}^{-1}\left(-x_{\mathrm{s} i},-x_{\mathrm{d} i}, l\right)$ added to the submatrix of $A^{-1}$ representing sire, dam and the individual. The coefficients $x_{\mathrm{s} i}$ and $x_{\mathrm{d} i}$ are genetic regressions of individual on parent so $x_{\mathrm{s} i}=1 / 2$ and $x_{\mathrm{d} i}=\left(1-F_{\mathrm{m}}^{2}\right) /\left(2-F_{\mathrm{m}}\right)$ or $1 / 2$ depending on whether the dam is a base dam or not. The term $m_{i}$ is the pseudo Mendelian sampling variance and is $\left.m_{i}=1-n_{\mathrm{b} i}\left(1-F_{\mathrm{m}}^{2}\right) / 4-F_{\mathrm{m}}^{2}\right)-\left(2-n_{\mathrm{b} i}\right) / 4$ with $n_{\mathrm{b} i}=1$ or 0 if the dam is a base dam or not. With the adjustment to the model the scaling factor reduces to $s_{\mathrm{Fc}}=\left(F_{\mathrm{m}}^{2} \sigma_{\mathrm{c}}^{2}+\sigma_{\mathrm{e}}^{2}+1\right) /\left(1-F_{\mathrm{m}}^{2}\right)$.

\section{An integrated Falconer-Willham model}

The variance of $y$ in model 4 (in main text) amounts to

$$
\sigma_{\mathrm{P}}^{2}=\sigma_{\mathrm{A}}^{2}+\sigma_{\mathrm{M}}^{2}+\sigma_{\mathrm{AM}}+2 F_{\mathrm{M}} \operatorname{cov}\left(A, y^{\prime}\right)+2 F_{\mathrm{m}} \operatorname{cov}\left(M, y^{\prime}\right)+F_{\mathrm{m}}^{2} \sigma_{\mathrm{P}}^{2}+\sigma_{\mathrm{C}}^{2}+\sigma_{\mathrm{E}}^{2}
$$

where

$$
\begin{aligned}
\operatorname{cov}\left(A, y^{\prime}\right) & =\operatorname{cov}\left(A, A^{\prime}\right)+F_{\mathrm{m}} \operatorname{cov}\left(A, A^{\prime \prime}\right)+F_{\mathrm{m}}^{2} \operatorname{cov}\left(A, A^{\prime \prime \prime}\right)+\ldots \text { etc } \\
& +\operatorname{cov}\left(A, M^{\prime}\right)+F_{\mathrm{m}} \operatorname{cov}\left(A, M^{\prime \prime}\right)+F_{\mathrm{m}}^{2} \operatorname{cov}\left(A, M^{\prime \prime \prime}\right)+\ldots \text { etc } \\
& +\left(\frac{1}{2}+\frac{1}{4} F_{\mathrm{m}}+\frac{1}{8} F_{\mathrm{m}}^{2}+\ldots \text { etc }\right) \sigma_{\mathrm{A}}^{2} \\
& +\left(\frac{1}{4}+\frac{1}{8} F_{\mathrm{m}}+\frac{1}{16} F_{\mathrm{m}}^{2}+\ldots \text { etc }\right) \sigma_{\mathrm{AM}} \\
& =\frac{1 / 2 \sigma_{\mathrm{A}}^{2}+1 / 4 \sigma_{\mathrm{AM}}}{1-F_{\mathrm{m}} / 2}=\frac{2 \sigma_{\mathrm{A}}^{2}+\sigma_{\mathrm{AM}}}{2\left(2-F_{\mathrm{m}}\right)}
\end{aligned}
$$

and

$$
\begin{aligned}
\operatorname{cov}\left(M, y^{\prime}\right) & =\operatorname{cov}\left(M, A^{\prime}\right)+F_{\mathrm{m}} \operatorname{cov}\left(M, A^{\prime \prime}\right)+F_{\mathrm{m}}^{2} \operatorname{cov}\left(M, A^{\prime \prime \prime}\right) \ldots \text { etc } \\
& +\operatorname{cov}\left(M, M^{\prime}\right)+F_{\mathrm{m}} \operatorname{cov}\left(M, M^{\prime \prime}\right)+F_{\mathrm{m}}^{2} \operatorname{cov}\left(M, M^{\prime \prime \prime}\right) \ldots \text { etc } \\
& =\left(1+\frac{1}{2} F_{\mathrm{m}}+\frac{1}{4} F_{\mathrm{m}}^{2}+\ldots \text { etc }\right) \sigma_{\mathrm{AM}} \\
& +\left(\frac{1}{2}+\frac{1}{4} F_{\mathrm{m}}+\frac{1}{8} F_{\mathrm{m}}^{2}+\ldots \text { etc }\right) \sigma_{\mathrm{M}}^{2} \\
& =\frac{\sigma_{\mathrm{AM}}+1 / 2 \sigma_{\mathrm{M}}^{2}}{1-F_{\mathrm{m}} / 2} \frac{4 \sigma_{\mathrm{AM}}+2 \sigma_{\mathrm{M}}^{2}}{2\left(2-F_{m}\right)}
\end{aligned}
$$

and hence

$$
\sigma_{\mathrm{P}}^{2}=\left[\sigma_{\mathrm{A}}^{2}+\sigma_{\mathrm{M}}^{2}+\sigma_{\mathrm{AM}}+\left\{\frac{2 \sigma_{\mathrm{A}}^{2}+5 \sigma_{\mathrm{AM}}+2 \sigma_{\mathrm{M}}^{2}}{2-F_{\mathrm{m}}}\right\} F_{\mathrm{M}}+\sigma_{\mathrm{C}}^{2}+\sigma_{\mathrm{E}}^{2}\right] /\left(1-F_{\mathrm{m}}^{2}\right)
$$


The factor $\left(s_{\mathrm{F}}\right)$ to scale the residual variances of the individuals with their dams' observations missing becomes

$$
\begin{aligned}
s_{\mathrm{F}}=\left[F_{\mathrm{m}}^{2} \frac{\sigma_{\mathrm{A}}^{2}}{\sigma_{\mathrm{E}}^{2}}+F_{\mathrm{m}}^{2}\right. & \frac{\sigma_{\mathrm{M}}^{2}}{\sigma_{\mathrm{E}}^{2}}+F_{\mathrm{m}}^{2} \frac{\sigma_{\mathrm{AM}}}{\sigma_{\mathrm{E}}^{2}} \\
& \left.+\left\{\frac{2 \sigma_{\mathrm{A}}^{2}+5 \sigma_{\mathrm{AM}}+2 \sigma_{\mathrm{M}}^{2}}{2-F_{\mathrm{m}}}\right\} \frac{F_{\mathrm{m}}}{\sigma_{\mathrm{E}}^{2}}+F_{\mathrm{m}}^{2} \frac{\sigma_{\mathrm{C}}^{2}}{\sigma_{\mathrm{E}}^{2}}+1\right] /\left(1-F_{\mathrm{m}}^{2}\right)
\end{aligned}
$$

Again this adjustment is based on phenotypic grounds. There are small additions to the maternal variance and additive-maternal covariance terms. These can be simply incorporated in the main model by using $y=A+F_{\mathrm{m}} A^{\prime \mathrm{c}}+M^{\prime \mathrm{c}}+D+C+E$ for individuals with unmeasured base dams, where $M^{\prime c}$ is an accumulated maternal value which equals $M^{\prime}+F_{\mathrm{m}} M^{\prime \prime}+F_{\mathrm{m}}^{2} M^{\prime \prime \prime}+\ldots$ etc. The relationship matrix for $M^{\prime c}$ and other maternal genetic variances is $A^{*}$, the relationship matrix for $A^{\prime c}$ and other additive values. 